\title{
Kenaf Reinforced PLA Composite Thermoforming: A Numerical Simulation
}

\author{
Abu Bakar Sulong ${ }^{1^{*}}$, Nabilah Afiqah Mohd Radzuan², Mohd Rizal \\ Mamat $^{1}$, Izdihar Tharazi ${ }^{1}$, Dulina Tholibon ${ }^{1}$, Radwan Dweiri $^{3}$, Mohannad Saleh \\ Hammadi $^{4}$
}

\author{
${ }^{1}$ Department of Mechanical and Materials Engineering, Faculty of Engineering and Built Environment, Universiti \\ Kebangsaan Malaysia, 43600 Bangi, Selangor, Malaysia. \\ ${ }^{2}$ Fuel Cell Institute, Universiti Kebangsaan Malaysia, 43600 UKM Bangi, Selangor, Malaysia. \\ ${ }^{3}$ Department of Materials Engineering, Al-Balqa Applied University, 19117 Al-Salt, Jordan. \\ ${ }^{4}$ Department of Mechanical Engineering, Hangzhou Dianzi University, China
}

Received 17 April 2018; accepted 27 August 2018, available online 30 October 2018

\begin{abstract}
Recent manufacturing developments, which focus on optimum product fabrication technique, including thermoforming, are time-consuming and cost-effective. Fundamental studies of the thermoforming process; especially in a uni-directional direction of Kenaf fiber composite, are still in their preliminary stages. Hence, a numerical simulation is performed to minimize experimental conduct. PAM-FORM software is used to model and simulate the thermoforming process, by studying the effects of processing parameters on the results of the simulation. The optimum thermoforming process parameters, in terms of temperature, puncher speed, puncher radius and composite thickness are determined via the design of the experiments. The output parameters, including composite thinning, shear angle and stress are analysed to identify the wrinkling defects, which are further analysed using Design-Expert software. The results demonstrate that, a temperature of $120{ }^{\circ} \mathrm{C}$, a puncher speed of $28.78 \mathrm{~m} / \mathrm{s}$, a puncher radius and composite thickness of $4 \mathrm{~mm}$ and $2 \mathrm{~mm}$, respectively is able to achieve minimum thinning and minimal shear angle during the thermoforming process.
\end{abstract}

Keywords: Numerical simulation, Kenaf composite, thermoforming process.

\section{Introduction}

Green composite materials have attracted a great deal of attention; especially in industrial and research fields. The benefits of applying these types of materials have already been recognized as an alternative to conventional automotive components (Alkateb et al. 2017). Focus on using natural fibers has grown rapidly, as this biodegradable green composite material is able to minimize global warming issues (Hao, Yuan \& Chen 2015). Studies indicate that various natural fibers are frequently used nowadays due to their attractive features; including high specific strength, low cost, low density, high stiffness, no hazard and low carbon missions (Jiang et al. 2011; Pervaiz \& Sain 2003). Materials, including kenaf, jute, and hemp are natural fibers that offer lightweight materials with 25 to $30 \%$ higher mechanical strength (Öztürk Ilker et al. 2010; Ramesh 2016). Studies show that kenaf fiber is a future candidate that is able to enhance the mechanical properties of composite materials (Ismail et al. 2018; Ochi 2008). Despite the selection of suitable natural fibers used as composite materials, the manufacturing process is the main issue to address (Low et al. 2017; Yaakob et al. 2015). Major industrial limitations include the drawback of using conventional manufacturing procedure, which are costly, inefficient and lengthy (Hao, Zhao \& Chen 2013; Low et al. 2017).

Thermoforming appears to be an efficient solution; as it is already used extensively to fabricate smooth material surface (Bernard et al. 2013). Thermoforming is often defined as a technique that results in thin wall plastic formations, due to clamp and heated above the melting temperature over a thin film (Sala, Cassago \& Di Landro 2002). This is crucial; especially in producing automotive components, such as dashboards and inner doors (Tholibon et al. 2016). However, the thermoforming process only acquires normal pressure, compared to conventional injection molding processes, which develops materials of constant thicknesses that are a major limitation (Hao, Yuan \& Chen 2015). The material's thickness depends on the temperature applied (Hao, Yuan \& Chen 2015). Meanwhile, the puncher speed and diameter often reflects kenaf composite performance (Hao, Zhao \& Chen 2013). Therefore, studying the parameters applied to the composite materials, using the thermoforming process, is a key element in developing excellent composite materials.

Regardless of the experiments conducted, study of numerical simulation has only been broadly mentioned 
during the last decade (Yaakob et al. 2015). Researchers tends to focus on the simulation as an alternative in predicting the experimental by providing a minimal failed trial (Fahmee et al. 2018). These ensure that the optimum parameters were applied when producing an excellent composite material performance. Moreover, this allows the minimum cost to be applied in fabricating the components. Studies have reported that plenty of numerical simulation software is able to simulate the processing. However, recent studies have indicated that PAM-FORM software offered a wide variety; especially when involved in detailing the composite's structure (Margossian, Bel \& Hinterhoelzl 2016; Wollmann et al. 2018). In this article, we investigate thermoforming parameters using a numerical simulation technique, via PAM-FORM software, to predict material thickness and shear angle to become the main aim of this study. In conjunction with obtaining excellent performance of kenaf composites, the experimental was conducted, as its output data will be applied as an input data in the simulations performed.

\section{Numerical Simulation Model}

A comprehensive drawing, using the 3D CATIA V5 software, was used to develop a geometry model of the lower blank holder, upper blank holder, and a puncher. These geometry models were determined based on the time frame and cost-efficiency attributes of the concept idea (Hussein 2014). The specific geometry model designs (shown in Fig. 1) were prepared in .CATPart format, which enables modification during the conducted simulation. The geometry models were then imported into the PAM-FORM software, in order to complete for the simulation analysis.

Later, the meshing process was performed automatically and the mechanical properties, including Young's modulus and Poisson ratio of the composite, were used as input data. These data inputs were determined based on experiments conducted using kenaf reinforced PLA composite materials. The attributes of rigid body, kinematics, contact, and loading, were defined for both puncher and blank holder models. Meanwhile, the initial thermal behavior was determined at $60^{\circ} \mathrm{C}$. At this stage, the solvers were initiated and simulation results were collected.

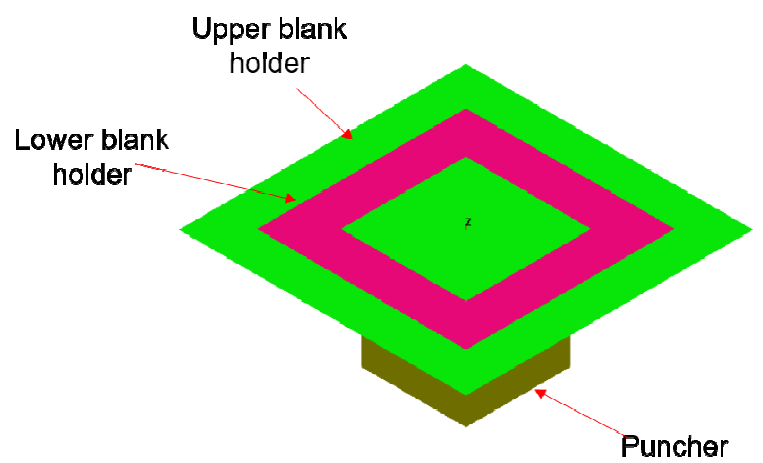

Fig. 1 Graphical image of puncher and holder position.

\subsection{Design of Experiment}

A full factorial design was used to identify the thermoforming parameters based on the numerical simulation analysis conducted (Yaakob et al. 2015). Table 1 lists the parameter used in this study based on the thermal behavior analysis and application needs. The design of experiment (DOE) was used to distinguish between factor interaction towards the thermal behavior and optimum output of thinning and shear angle (Fahmee et al. 2018). The parameters and factors were determined based on studies of kenaf composite and thermoforming processes. An identical parameter was acquired to minimise defects during the formation process and developed an excellent performance of kenaf fiber that was suitable to applied in automotive industries. Hence, the parameters, in terms of temperature, puncher speed, puncher diameter and composite thickness, were studied. A study was conducted using a 2-level full factorial design (Design-Expert software) to obtain a suitable number of runs before analysis using ANOVA. Each of the parameters indicated 17 runs based on a 2-level factorial design; which were later used to determine the simulation output (Al-Hadeethi, Al-Nimr \& Al-Safadi 2015).

Table 1 Factor and levels of DOE for simulation analysis.

\begin{tabular}{ccc}
\hline Parameter & Level 1 & Level 2 \\
\hline Temperature $\left({ }^{\circ} \mathrm{C}\right)$ & 60 & 120 \\
Puncher speed $(\mathrm{m} / \mathrm{s})$ & 10 & 30 \\
Puncher diameter $(\mathrm{mm})$ & 2 & 4 \\
Composite thickness $(\mathrm{mm})$ & 2 & 4 \\
\hline
\end{tabular}

\subsection{Material's Feed}

Polylactide acid (PLA) reinforced kenaf fiber was used in this study. The kenaf fiber used has an initial degradation temperature of $327.9^{\circ} \mathrm{C}$ with a weight loss of $70.2 \%$. Meanwhile, the PLA matrix exhibited a melting temperature of $172{ }^{\circ} \mathrm{C}$, initial degradation temperature of $342.8{ }^{\circ} \mathrm{C}$ and weight loss of $92.07 \%$ (Tholibon et al. 2016). The kenaf reinforced PLA composite, at 16302 $\mathrm{MPa}$, with density of $1.21 \mathrm{~kg} / \mathrm{m}^{3}$ and Poisson ratio of 0.3 was used as a material feeder in this study (Tholibon et al. 2016). This material was selected for its potential in high mechanical properties with excellent Young's modulus and low in density; which benefits fabricating automotive components. Kenaf reinforced PLA composite, at compositions of $50 \mathrm{wt} . \%$ of kenaf fibers and $50 \mathrm{wt} \%$ of PLA, were applied in this study, as they obtained excellent mechanical properties (as reported in the previous studies by Oksman, Skrifvars \& Selin 2003; Tholibon et al. 2016). The direction of kenaf fiber orientation remained at $0^{\circ}$ for its ability to produce strengthened composite materials (Hobbie et al. 2003). 


\subsection{Materials Characterization}

Kenaf reinforced PLA composites, prepared using a hot press machine, will undergo tensile testing at different temperature ranges (i.e, $60{ }^{\circ} \mathrm{C}, 90{ }^{\circ} \mathrm{C}$ and $120{ }^{\circ} \mathrm{C}$ ). The samples were prepared at a size of $115 \mathrm{~mm} \times 20 \mathrm{~mm} \times 2$ mm (L x W x T) based on the ASTM D3039. The tensile test was performed using a Zwick Roell UTS Machine $(100 \mathrm{kN})$ with an attached furnace. A strain gauge was placed in the middle area of the sample and secure using KYOWA glue. Data was collect using the KYOWA PCD0-3008 interface. The crosshead speed applied in this testing is $5 \mathrm{~mm} / \mathrm{min}$ at $65 \mathrm{~mm}$ gauge length.

\section{Results and Discussion}

The tensile testing conducted exhibited an excellent performance (as shown in Table 2); especially at a processing temperature of $120^{\circ} \mathrm{C}$. Table 2 reports that the Young's modulus of kenaf composite deteriorates as the temperature increases; with a percentage drop of $21.9 \%$ from $11,667 \mathrm{MPa}$ to $9,107 \mathrm{MPa}$; which is a significant drop of more than $10 \%$. This drop influences the simulation analysis as Young's modulus symbols of material strength. Meanwhile, the decrease of Young's modulus value is attributable to the PLA, which is a thermoplastic material whose properties tent to decay as the temperature increases (Biron 2016; Throne, J.L. 1996. Technology of Thermoforming. Throne, J.L. (eds.).First. t.tp: Hanser/Gardner Publications 1996). Furthermore, Table 2 lists the Poisson ratios obtained from the tensile test that indicate a significant fall of $57.7 \%$ from 0.16 to 0.06 , as the temperature increased from $60{ }^{\circ} \mathrm{C}$ to $90{ }^{\circ} \mathrm{C}$. This is explained by the temperature dependency and cross-linked polymer materials, whose higher Poisson's ratio obtained with respect to temperature decrease (Raja \& Sethuraman 2008). The low Poisson's ratio results during low deformation strengthened the composite materials (Raja \& Sethuraman 2008). These results were also reported in other studies that indicated Poisson;s ratio exhibited viscoelastic behavior as the value decreased at higher temperatures; sufficient for a rubbery behavior (Dörr et al. 2017).

Table 2 Young's modulus at different temperature.

\begin{tabular}{ccc}
\hline Temperature $\left({ }^{\circ} \mathrm{C}\right)$ & $\begin{array}{c}\text { Young } \\
\text { modulus } \\
(\mathrm{MPa})\end{array}$ & Poisson ratio \\
\hline 60 & 11,667 & 0.16 \\
90 & 9,107 & 0.06 \\
120 & 7,623 & 0.09 \\
\hline
\end{tabular}

Based on the experiments conducted, the simulations were performed at temperature of $60^{\circ} \mathrm{C}$ to $120^{\circ} \mathrm{C}$ to identify the optimum thermoforming process parameters. The Young's modulus and Poisson ration from the experiments were used as input data in the simulations. The thermoforming process studies reported that at 120 ${ }^{\circ} \mathrm{C}$, the thinning defects would be minimized; thus producing a homogenous end-product. The thinner composite materials, of $0.149 \mathrm{~mm}$ and shear angle of $0.122^{\circ}$, were reported as the temperature rise; which minimized the distortion produced. Moreover, the highest tensile strength reported at four edges with $39 \mathrm{MPa}$ minimized the failure potential that occurred due to the high shear concentration. Meanwhile, the results show that lower puncher speed result in higher composite defects; because of the unhomogenized flow throughout the thermoforming process. A puncher speed of $30 \mathrm{~m} / \mathrm{s}$ is the optimum speed that results in a maximum composite thickness of $0.013 \mathrm{~mm}$. However, the puncher radius did not affect the shear angle or composite thickness.

The thermal behavior effect on composite thickness was determined using ANOVA analysis. The results indicate that temperature and puncher diameter gave a significant impact on the thermoforming process; with percentage contributions of $50.2 \%$ and $34.9 \%$, respectively. The mathematical model showed that the Rsquared value of composite thickness was 0.9929 (as shown in Fig. 2a); which is in an acceptable range. Moreover, the small differential between the experimental and the simulation demonstrate an excellent correlation. Meanwhile, Fig. 2 (b) demonstrates that temperature and puncher diameter influenced the composite shear angle; as percentage contributions of $47.6 \%$ and $39.4 \%$, respectively.

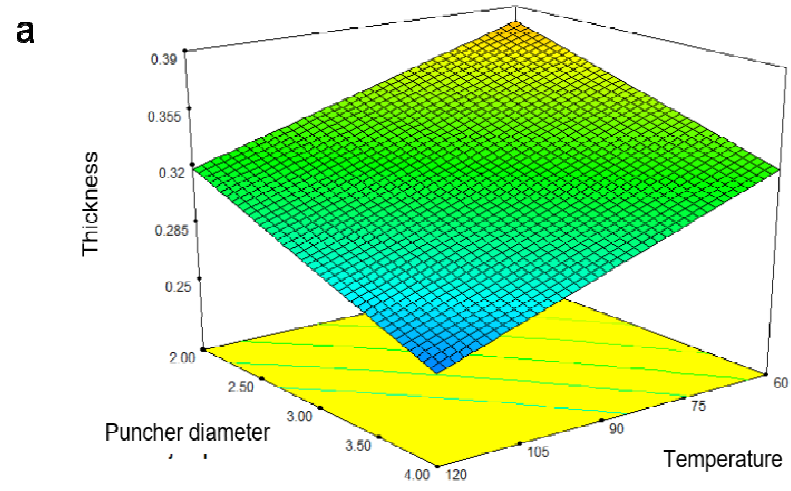

b

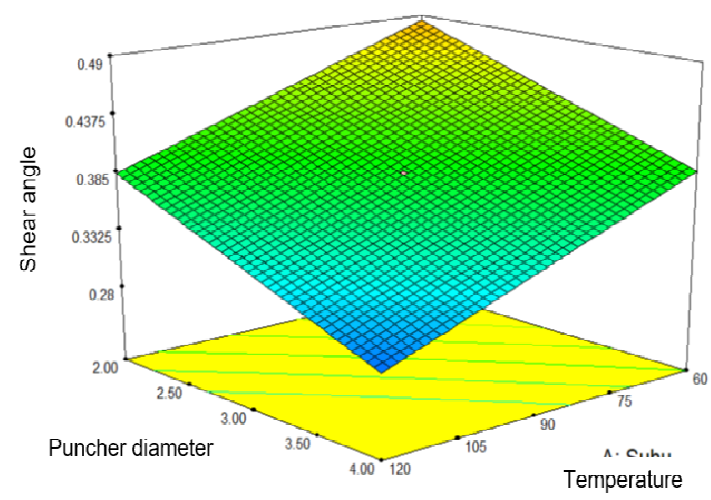

Fig. 2 Plot of (a) thickness and (b) shear angle response of experimental and simulation values 
International Journal of Integrated Engineering: Special issue 2018:

Mechanical Engineering, Vol. 10 No. 5 (2018) p. 15-20

(c) Penerbit UTHM

DOI: https://doi.org/10.30880/ijie.xx.xx.xxxx.xx.xxxx

Table 3 Experimental data responses for thickness and shear angle

\begin{tabular}{ccccccc}
\hline $\begin{array}{c}\text { Number } \\
\text { of runs }\end{array}$ & $\begin{array}{c}\text { Blank } \\
\text { temperature } \\
\left({ }^{\circ} \mathrm{C}\right)\end{array}$ & $\begin{array}{c}\text { Puncher } \\
\text { speed } \\
(\mathrm{m} / \mathrm{s})\end{array}$ & $\begin{array}{c}\text { Puncher } \\
\text { diameter } \\
(\mathrm{mm})\end{array}$ & $\begin{array}{c}\text { Blank } \\
\text { thickness } \\
(\mathrm{mm})\end{array}$ & $\begin{array}{c}\text { Thickness } \\
(\mathrm{mm})\end{array}$ & $\begin{array}{c}\text { Shear } \\
\text { angle }\left({ }^{\circ}\right)\end{array}$ \\
\hline 1 & 90 & 20 & 3 & 3 & 0.319835 & 0.386886 \\
\hline 2 & 60 & 30 & 2 & 4 & 0.412227 & 0.536325 \\
\hline 3 & 120 & 10 & 2 & 2 & 0.313015 & 0.382523 \\
\hline 4 & 60 & 30 & 2 & 2 & 0.381414 & 0.49449 \\
\hline 5 & 60 & 30 & 4 & 4 & 0.354115 & 0.431061 \\
\hline 6 & 60 & 30 & 4 & 2 & 0.328791 & 0.389434 \\
\hline 7 & 60 & 10 & 4 & 4 & 0.333517 & 0.403258 \\
\hline 8 & 120 & 30 & 4 & 4 & 0.287029 & 0.324318 \\
\hline 9 & 60 & 10 & 2 & 4 & 0.363227 & 0.450197 \\
\hline 10 & 60 & 10 & 2 & 2 & 0.364703 & 0.460208 \\
\hline 11 & 120 & 30 & 2 & 2 & 0.306529 & 0.372334 \\
\hline 12 & 60 & 10 & 4 & 2 & 0.305447 & 0.353999 \\
\hline 13 & 120 & 30 & 4 & 2 & 0.237809 & 0.257212 \\
\hline 14 & 120 & 10 & 4 & 4 & 0.2655 & 0.295646 \\
\hline 15 & 120 & 10 & 4 & 2 & 0.23898 & 0.259089 \\
\hline 16 & 120 & 30 & 2 & 4 & 0.342621 & 0.415307 \\
\hline 17 & 120 & 10 & 2 & 4 & 0.315141 & 0.369592 \\
\hline
\end{tabular}

Referring to the experimental process parameters, which are $120{ }^{\circ} \mathrm{C}$, puncher speed of $30 \mathrm{~m} / \mathrm{s}$, puncher diameter of $4 \mathrm{~mm}$ and composite thickness $2 \mathrm{~mm}$, the minimum thickness obtained was $0.238 \mathrm{~mm}$ and of $0.255^{\circ}$. As listed in Table 3, they demonstrate that run number 13 obtained the minimum thickness with the lowest shear angle. These phenomenon are explained by the previous researcher using the plug-assisted thermoforming process for polystyrene applications that indicated these behavior related to the shear rate experienced by the materials that attribute to the temperature applied (Bernard et al. 2013; O'Connor et al. 2013). Meanwhile, the simulation conducted obtained a thickness value of $0.2406 \mathrm{~mm}$ and shear angle of $0.2588^{\circ}$ (as shown in Fig. 3). These indicated that the percentage difference between the experimental data and the simulation data are $0.58 \%$ for thickness and $1.1 \%$ of shear angle. These explain that the PAM-FORM simulation conducted was able to predict the experiment; hence minimizing the number of runs and costeffectiveness.
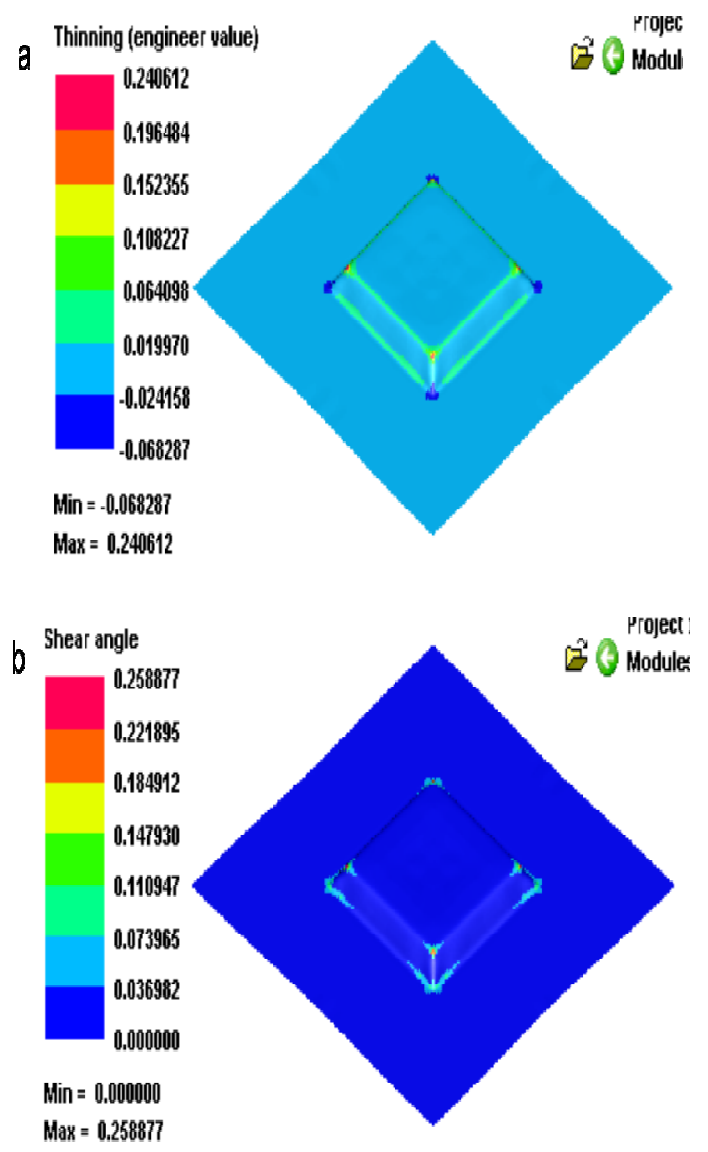

Fig. 3 PAM-FORM simulation response of (a) thinning and (b) shear angle 


\section{Summary}

The PAM-FORM simulation was studied to obtain optimum thermoforming processing parameter that are cost and time-effective based on the tensile tests conducted. The experimental results reported that the Young's modulus of $7,623 \mathrm{MPa}$ and Poisson's ratio of 0.09 were obtained at a temperature of $120^{\circ} \mathrm{C}$. Hence, based on the results obtained, the simulation conducted shows an optimum puncher speed parameter of 28.78 $\mathrm{m} / \mathrm{s}$, puncher diameter of $4 \mathrm{~mm}$ and composite thickness of $2 \mathrm{~mm}$ at a temperature of $120^{\circ} \mathrm{C}$. The numerical analysis indicates that the thinning and shear angle is able to be simulated; and thus, is able to reduce or eliminate experimental process errors. However, validation of the numerical simulation with real experimental is needs to be carried out in the future. It can be concluded that the numerical simulation successfully conducted for thermoforming part. It can therefore be used in automotive applications for components thermoforming.

\section{Acknowledgment}

The authors would like to thank the Ministry of Higher Education Malaysia (MOHE) for the funding under grant number LRGS/TD/2012/USM-UKM/PT/05 and FRGS/1/2017/TK03/02/1.

\section{References}

[1] Al-Hadeethi, F., Al-Nimr, M. \& Al-Safadi, M. Using the multiple regression analysis with respect to ANOVA and 3D mapping to model the actual performance of PEM (proton exchange membrane) fuel cell at various operating conditions. Energy, 90 2015, pp. 475-482.

[2] Alkateb, M., Sapuan, S.M., Leman, Z., Jawaid, M. \& Ishak, M.R. Energy absorption capacities of kenaf fibre-reinforced epoxy composite elliptical cones with circumferential holes. Fibers and Polymers, 18(6) 2017, pp. 1187-1192.

[3] Bernard, C.A., Correia, J.P.M., Bahlouli, N. \& Ahzi, S. Numerical Simulation of Plug-Assisted Thermoforming Process: Application to Polystyrene. Key Engineering Materials, 554-557 2013, pp. 1602-1610.

[4] Biron, M. Thermoplastic. Material Selection for Thermoplastic Parts, 2016, pp. 77-111.

[5] Dörr, D., Schirmaier, F.J., Henning, F. \& Kärger, L. A viscoelastic approach for modeling bending behavior in finite element forming simulation of continuously fiber reinforced composites. Composites Part A: Applied Science and Manufacturing, 94 2017, pp. 113-123.

[6] Fahmee, E., Jamal, A., Hashim, M.Y., Othman, M.H., Mohd, O., Marwah, F., Amin, A.M. \& Johar, M.A. Optimization of Alkali Treatment Condition on Tensile Properties of Kenaf Reinforced Polyester Composite Using Response Surface Method. International Journal of Integrated Engineering, 10(1) 2018, pp. 40-46.
[7] Hao, A., Yuan, L. \& Chen, J.Y. Notch effects and crack propagation analysis on kenaf/polypropylene nonwoven composites. Composites Part A: Applied Science and Manufacturing, 73 2015, pp. 11-19.

[8] Hao, A., Zhao, H. \& Chen, J.Y. Kenaf/polypropylene nonwoven composites: The influence of manufacturing conditions on mechanical, thermal, and acoustical performance. Composites Part B: Engineering, 54(1) 2013, pp. 44-51.

[9] Hobbie, E.K., Wang, H., Kim, H., Lin-Gibson, S. \& Grulke, E.A. Orientation of carbon nanotubes in a sheared polymer melt. Physics of Fluids, 15(5): 2003, pp. 1196-1202.

[10] Hussein, H.M.A. Computer aided blanking die design using CATIA. Procedia CIRP, 18 2014, pp. 96-101.

[11] Ismail, A.E., Sadikin, A., Nasrull, M., Rahman, A., Mahzan, S., Salleh, S., Ahmad, S. \& Baharudin, M. Crushing Performances of Axially Compressed Woven Kenaf Fiber Reinforced Cylindrical Composites. International Journal of Integrated Engineering, 10(1) 2018, pp. 189-195.

[12] Jiang, W., Sun, L., Hao, A. \& Yan Chen, J. Regenerated cellulose fibers from waste bagasse using ionic liquid. Textile Research Journal, 81(18) 2011, pp. 1949-1958.

[13] Low, J.H., Ghanbari, T., Aizan, W., Abdul, W. \& Rohah, A. Preparation and Characterization of Kenaf Papers Reinforced with Tapioca Starch: Physicomechanical and Morphological Properties Preparation and Characterization of Kenaf Papers Reinforced with. Journal of Natural Fibers, 2(15) 2018, pp. 191-203.

[14] Margossian, A., Bel, S. \& Hinterhoelzl, R. On the characterisation of transverse tensile properties of molten unidirectional thermoplastic composite tapes for thermoforming simulations. Composites Part A: Applied Science and Manufacturing, 88 2016, pp. 48-58.

[15] O’Connor, C.P.J., Martin, P.J., Sweeney, J., Menary, G., Caton-Rose, P. \& Spencer, P.E. Simulation of the plug-assisted thermoforming of polypropylene using a large strain thermally coupled constitutive model. Journal of Materials Processing Technology, 213(9) 2013, pp. 15881600.

[16] Ochi, S. Mechanical properties of kenaf fibers and kenaf/PLA composites. Mechanics of Materials, 40(4-5) 2008, pp. 446-452.

[17] Oksman, K., Skrifvars, M. \& Selin, J.-F. Natural fibres as reinforcement in polylactic acid (PLA) composites. Composites Science and Technology, 63 2003, pp. 1317-1324.

[18] Öztürk Ilker, I., Irmak, S., Hesenov, A. \& Erbatur, O. Hydrolysis of kenaf (Hibiscus cannabinus L.) stems by catalytical thermal treatment in subcritical water. Biomass and Bioenergy, 34(11) 2010, pp. 1578-1585.

[19] Pervaiz, M. \& Sain, M.M. Carbon storage potential 
in natural fiber composites. Resources, Conservation and Recycling, 39(4) 2003, pp. 325340.

[20] Raja, P.B. \& Sethuraman, M.G. Natural products as corrosion inhibitor for metals in corrosive media A review. Materials Letters, 62(1) 2008, pp. 113116.

[21] Ramesh, M. Kenaf (Hibiscus cannabinus L.) fibre based bio-materials: A review on processing and properties. Progress in Materials Science, 78 2016, pp. 1-92.

[22] Sala, G., Cassago, D. \& Di Landro, L. A numerical and experimental approach to optimise sheet stamping technologies: Polymers thermoforming. Materials and Design, 23(1), 2002, pp. 21-39.

[23] Tholibon, D., Sulong, A.B., Muhammad, N., Ismail, N.F., Tharazi, I. \& Md Radzi, M.K.F.. Tensile properties of unidirectional kenaf fiber polypropylene composite. Jurnal Teknologi, 78(69)2016, pp. 101-106.
[24] Throne, J.L. (1996). Technology of Thermoforming. Throne, J.L. (eds.). First. t.tp: Hanser/Gardner Publications, I. Technology of Thermoforming.

[25] Wollmann, T., Hahn, M., Wiedemann, S., Zeiser, A., Jaschinski, J., Modler, N., Ben Khalifa, N., Meißen, F. \& Paul, C.. Thermoplastic fibre metal laminates: Stiffness properties and forming behaviour by means of deep drawing. Archives of Civil and Mechanical Engineering, 18(2) 2018, pp. 442-450.

[26] Yaakob, M.Y., Husin, M.A., Ching, L.Y. \& Hearyip, S. A Review on Potential of Development New Weave Pattern Design using Glass Fiber and Kenaf Fiber for Intraply Composite. International Journal of Integrated Engineering, 7(2) 2015, pp. $5-13$. 